\title{
The Perception and Practice of EFL Teachers in Teaching Vocabulary Using Communicative Language Teaching (CLT)
}

\author{
Dr.Kitaw Joseph Zewdu* \\ College of social Science \& Humanities, \\ Department of English Language \& Literature, Debre Markos University, Ethiopia \\ p.o.box 269,Debre Markos, Ethiopia \\ Fentye Molla \\ West Gojjam Zone, Achefer District, Liben secondary \& preparatory school, Ethiopia
}

\begin{abstract}
The purpose of this study was to investigate EFL teachers' perception and practice of using CLT in teaching vocabulary in an Ethiopian secondary school. It focused on identifying the teachers' perception to vocabulary teaching, to assess how often they teach it using CLT, and identify the challenges they face in teaching vocabulary using CLT. In order to achieve these objectives, descriptive survey design was employed. The participants of the study were $10 \mathrm{EFL}$ teachers selected using comprehensive sampling. As data gathering instruments, questionnaire, observation, and interview were used. Descriptive statistics techniques - frequency, percentage and mean- were applied for data analysis. The interview data was also analyzed using themes. The results indicated that EFL teachers have positive perception to teach vocabulary using CLT although their actual classroom practice does not match with their perceptions. They did not use the techniques regularly to present the vocabulary lessons. Moreover, the major problems identified as obstacles in the teaching and learning process were large class size, lack of interest of students and poor quality of the textbook. The issue of teaching vocabulary using CLT remained impractical. Thus, stakeholders have to work hard to reverse the situation of language teaching in these schools.

Keywords - CLT, perception, practice, vocabulary, EFL teaching
\end{abstract}

DOI: $10.7176 / \mathrm{JLLL} / 68-01$

Publication date:May $31^{\text {st }} 2020$

\section{INTRODUCTION}

In contrast to the era of Grammar Translation method and Direct Method of language teaching, vocabulary teaching and learning has got more attention in Communicative Language Teaching (CLT) since the 1970's (Yuling 2005; Melaku, 2019).This is due to the shift of teaching language as a set of forms (grammatical, phonological, lexical) to functional system for a range of communicative purposes (Shejabala, 2006). Similarly, Lu (2017) reported that traditionally vocabulary study has received less attention in second language (L2) pedagogy than any of the four language skills, and grammar in many US schools until recently. In brief, vocabulary refers to the whole of words and set phrase in English language which are important for academic and social communication (Pamintuan, et.al., 2018). Again, Muncie (2002) in Lu (2017) observed that vocabulary study is not given due attention in many teachers' training programs as the language programs seem to be unclear about the central role of vocabulary in language acquisition.

Vocabulary is essential in expressing ideas and thoughts. In relation to this point, Wilkins (1976) argues 'without grammar, there are few things we can express; while without vocabulary, there is nothing we can express.' This shows that insufficient vocabulary in a language learning environment leads to breakdown in communication. Without the mediation of vocabulary, no amount of grammatical or other types of linguistic knowledge can be employed in second language communication. Citing other researchers (Folse, 2008, Nation, 2013, and Hinkel , 2015), $\mathrm{Lu}$ (2017) reported that the vocabulary size students have highly affects the development of their writing skills in language learning classrooms. Further more, this is true not only for writing activities but also for other language skills in the EFL setting. In short, to be effective in a communication environment, the language learners have to be rich in vocabulary to express their ideas accurately and fluently.

However, knowing vocabulary alone without applying for communicative purposes is meaningless because only forms do not help to develop communicative competence. As Richards and Rodgers (2001) point out, vocabulary teaching in CLT focuses on meaning rather than form since the emphasis is on achieving effective communication on meaning based approach. Citing other researchers (Schmitt 2000, Coady \& Huckin, 2000), Melaku (2019) reported that in contrast to teaching vocabulary in isolated word lists, nowadays there are lots of new techniques such as contextualization, sense relationships, networking, and collocation to teach vocabulary in a meaningful manner. These techniques are useful to increase the lexical competence of students and which in turn develops the communicative competence of learners in using the four language skills.

Teachers are expected to create suitable language environment so as to help students use the language for problem solving activity. This motivates them to pick up the language since they practice by considering actual 
situations and introducing their background experience. In relation to this, Ansarey (2012) stated that the primary focus of CLT is to facilitate learners' efforts in creating meaning not in developing grammatical structures or getting native-like pronunciation. This means that success of learning a foreign language depends on how well students have developed their communicative competence.

Having grammatical knowledge alone cannot be a guarantee to take part in communication; in addition, sufficient amount of words are needed to use the language for communication (Savignon, 2002). In relation to the teaching experience and personal observation of the researchers of this study, it was learnt that English language teachers did not give enough attention to vocabulary lesson in their respective classrooms, and they did not teach vocabulary using meaning-focused approach. They also did not give attention for vocabulary in their classroom tests and examinations-implying the negative wash back effects of language tests on vocabulary lesson. As a result, students did not pay attention to the teaching and learning of vocabulary lesson. They did not have a lot of vocabulary to their level for smooth communication in the four language skills. This is the gap of this research that initiated the researchers to conduct the study. Thus, they were initiated to study what the EFL teachers' perception and practice look like in their EFL classrooms. The researchers felt that there is incongruence between the beliefs and actual practice of EFL teachers in relation to vocabulary lesson.

Citing Dobson and Dobson (1983), Lu (2017:21) reported that "any real improvement in schooling will occur only when teachers are experiencing beliefs-practice congruency". Therefore, it is of great importance to explore the gap whether there is a discrepancy between

English language teachers' perception and actual practice in vocabulary teaching; this helps to find solutions to minimize this discrepancy.

It is a common knowledge that the beliefs individuals have about things will influence their thinking and behavior to these issues. In connection with this, citing Pajares (1992), and Bryan (2012), Almalki (2014) indicated that the beliefs teachers have about language instruction highly influence what they do in their professional practice in ELT classrooms. Further more, Pajares (1992:307) in Almalki (2014) added: "beliefs are best indicators of the decisions individuals make throughout their lives". For example, in a study by Farrell \& Bennis (2013) and Phipps \& Borg (2009) in Lu (2017), it was observed that self-expressed teaching beliefs of teachers that they claimed before do not always match with their actual classroom practices. Thus, this kind of problem is seen in EFL settings; so, this issue needs to be a focus of language research; it needs timely exploration because it shifts from time to time due to various factors.

\subsection{Statement of the problem}

In Communicative Learning Teaching (CLT), the main concern is making students effective in different communication settings using the target language. Thus, having a good number of vocabularies is necessary. When students know enough number of words to use in the learning tasks, they will be at ease to express their ideas and feelings to their friends and their teacher in an effective manner. Citing Nation (2013:60), Lu (2017) mentioned that knowing a word include knowledge about "form (spoken/written/word parts), meaning (form and meaning/ concept and referents/ associations), and use (grammatical functions/ collocations/ constraints on use) from the general level".

Their interaction will be smooth and effective. This facilitates the teaching and learning process in the English language classroom. Accordingly, the way vocabulary is taught matters a lot in this regard. If students are taught vocabulary using CLT, they are likely to learn more new words and use the others they already know as part of their memory (i.e., turning passive vocabulary to active vocabulary).

However, there are many problems in the EFL classrooms in relation to vocabulary teaching. If we see teacher-related variables, part of the problem lies on lack of awareness of teachers about the variety of vocabulary teaching techniques. This is lack of training in vocabulary teaching methods; the other is related to attitudinal issue that teachers hold towards the relevance of vocabulary study in the language learning process. If they have low opinion of the importance of vocabulary in language learning, they are unlikely to teach it intensively to benefit students.

The other problem is environmental challenge in using English as a foreign language. Out of the classroom, there are no places to use the language for a real purpose communication. However, language researchers like Krashen (1981) recommend increasing the language input in a real-life situation. Therefore, to fill this gap the students and teachers can use the advantage of computer and mobile technology. For example, citing Wu (2014) and Lin (2017), Pamintuan, et.al. (2018) showed the advantages of computer and mobile applications of the digital technology to help teachers and students engage in interactive language environment to minimize the limitations of traditional language classes. Thus, digital technology can be exploited a lot for pedagogical purposes in teaching vocabulary in EFL classes.

Vocabulary plays an essential role in expressing ideas and thoughts. McCarthy (1990) states: "the single biggest component of any language course is vocabulary. No matter how well the students learn grammar, no matter how well the sounds of L2 are mastered, without words to express a wide range of meanings, 
communication in L2 cannot happen in any meaningful way." From this point we can understand that studying vocabulary is mandatory for students to improve their communicative competence. Citing Datzman (2011), Pamintuan, et.al. (2018) reported that acquiring vocabulary is a difficult task for both students and teachers in a language learning class. Thus, it needs a serious attention in planning and executing accordingly.

In an experimental study conducted in a local secondary school, it was found out that communicative language teaching (CLT) was effective to increase students' vocabulary knowledge and use in the communicative situations (Tadesse ,2016). Working in real communication activities in the language learning process helps students to enhance their learning by focusing on the meanings of tasks, not on its structures or forms (Brown, 2000; Richards and Rodgers, 2001). If we teach vocabulary forms only without the focus of meaningful communication, it is difficult to enhance the students' communicative competence.

More importantly, the vocabulary knowledge students have will highly determine the academic success of students in schools in which English is the medium of instruction like the case in Ethiopia. That is to say, the students' comprehension of a text is inversely proportional to the difficulty of words in a text.

Therefore, English language teachers' classroom practice should focus on relating vocabulary teaching with CLT. This helps to expose students to lexical sets in authentic and meaningful contexts (Brumfit and Johnson, 1979). That is following the general principle of CLT, i.e., using the language in order to learn it, and focusing on performance than grammatical competence only.

In relation to local studies, Wassihune (2016) carried out a research on assessing the practice of vocabulary teaching strategies in EFL classes in three primary schools. It was found out that the only strategy frequently used was contextual clue strategies and moreover the teachers were not aware of the theoretical knowledge of other vocabulary teaching strategies in EFL classes. In another similar study in a secondary school, Miressa (2014) reported that there was lack of theoretical knowledge of teachers on the techniques of vocabulary study.

In other studies, Abebe (2009) and Nayzgi (2016) reported that EFL teachers did not use many alternative strategies in their vocabulary instruction as they thought other strategies were less important in their beliefs; teachers also did not use an organized approach in using vocabulary teaching strategies. Moreover, Daniel (2010) reported that EFL teachers had positive perception to CLT but did not practice it properly in their actual classroom performance. In another study which was conducted in a secondary school in Addis Ababa, Melaku (2019) reported that English language teachers did not use various vocabulary teaching techniques in their classes.

From the above local studies, we can conclude that EFL teachers did not use many types of vocabulary teaching strategies and in some of the studies it was reported that teachers' beliefs did not match with their classroom practice. More over, due to low weight given in tests and examinations, vocabulary teaching did get due attention in the Ethiopian language classes.

As part of the domain of psychological variables - teachers' perceptions which influence language teachers' practice are not given due attention by the language researchers. As to the knowledge of the researchers of this study, little attention is paid to these issues in the studies conducted locally. Assessing the daily practices of EFL teachers in vocabulary instruction is important since perceptions/beliefs of English language teachers may not match with their classroom practices and their practices also may not reflect the type of vocabulary teaching techniques recommended by syllabus writers in the students' textbook.

Generally, it is clear from the literature that the perceptions EFL teachers have will highly affect their classroom practice either positively or negatively. In addition, assessing the classroom practices of EFL teachers is also useful to generate information about the teaching and learning process so that the necessary feedback could be provided for the stakeholders. Thus, bearing in mind this idea, the project was carried out to answer the following research questions:

$\checkmark \quad$ What are the perceptions of EFL teachers on Communicative Language Teaching (CLT) principles in teaching vocabulary?

$\checkmark$ How often do EFL teachers practice Communicative language teaching in vocabulary instruction?

$\checkmark$ What are the problems that affect EFL teachers in teaching vocabulary in their classrooms?

\subsection{Objective of the study}

The main objective of the study was to assess the perception and practice of EFL Teachers in teaching vocabulary using communicative language teaching. Specifically, it focused on the following purposes:

$\checkmark$ to identify the perceptions of EFL teachers in teaching vocabulary using Communicative Language Teaching (CLT) principles

$\checkmark$ to understand to what extent EFL teachers practice Communicative language teaching in vocabulary instruction

$\checkmark$ to list down the major problems that affect EFL teachers in teaching vocabulary in their classrooms

\subsection{Significance of the study}

This study would be significant for the following bodies. Firstly; it would provide a better understanding for 
teachers to evaluate the method they are using to teach vocabulary, Secondly; it would be helpful for students to learn vocabularies in relation with CLT. Thirdly; it would be helpful for adding to the body of literature on vocabulary teaching in EFL classes and serves as a reference for other researchers.

\subsection{Scope of the study}

This study was delimited to concept, time and place in its progress. Conceptually, it focused on assessing the congruence between perception and practice of teachers in teaching vocabulary using CLT; more over,it also list down major problems they faced. The participants of the study were all EFL teachers who are working in Liben secondary and preparatory school in East Gojjam zone, Ethiopia. The data was collected in the school in the 2019 academic year.

\section{METHODS OF THE STUDY}

The study followed descriptive research design. It is helpful to identify the present conditions and needs (Sharma, 2000). The population of the study is 10 English language teachers who were teaching in Liben secondary and preparatory school in East Gojjam zone, Ethiopia. All of these teachers were involved using comprehensive sampling technique. To gather relevant data from these participants, questionnaire, observation and interview were employed as data gathering tools.

A five-point Likert-scale questionnaire was designed to investigate the EFL teachers' perception and practice of using CLT in teaching vocabulary. It was 38 in number (both open-ended and close-ended items) and adapted from Fosch (2017),Richards (2006) and Miressa (2014). As part of the components of the questionnaire,4 were background items, 8 were items of perceptions of EFL teachers, 14 were items on teachers' practice, and 12 focused on the challenges of applying CLT in teaching vocabulary.

To get first-hand information about the practice of teachers in the classroom, observation was employed. For this purpose, structured observation checklist was used by adapting from Miressa (2014), and Karim (2004). The researcher and the co-observer acted as non-participant observers during data collection in the classroom. Thus, three observations were made for each English language teacher and totally 30 classroom observations were done in two months' time.

To supplement the other data gathering tools, interview was made with all 10 teachers. It was a semistructured interview type. It is useful to enhance the understanding of data and makes the data collection process more systematic (Lynch,1996).It was designed to get data on the perceptions of teachers towards the use of CLT in teaching vocabulary. It was mainly for crosschecking the response obtained in the questionnaire.

In the data collection process, first classroom observation was made before distributing the questionnaire to avoid data contamination. Next, after adapting the questionnaire items, the questionnaire was distributed to the teachers. Finally, interview was made with the teachers.

For data analysis and interpretation, descriptive statistics (mean, frequency and percentage) was employed.

\section{DISCUSSION OF FINDINGS}

1. Questionnaire results on teachers' perceptions on CLT principles in teaching vocabulary

Based on the results of table one, the mean value for each item was calculated and finally the grand mean was also obtained. The mean scores of the above table are interpreted as follows (Oxford, 1990).

\section{$\checkmark \quad 1.00 \quad 2.49$ low $\quad 2.5 \quad 3.49$ medium $\quad 3.5 \quad 5.00$ high}

Among the eight items, with the exception of one item which is medium, the rest are in the range of high value including the grand mean. This shows that the teachers have high (strong) perceptions to the use of CLT principles in teaching vocabulary. The teachers are in the opinion that the vocabulary activities should expose students to interactive activities, teachers play facilitative role in the process, the task should be meaningful for students, and thus the vocabulary teaching materials are expected to be more authentic for meaningful interaction and active learning; in this regard, both the students and teachers are expected to play active roles as part of the student-centered interactive class.

Moreover, from the interview with the participants, all of them have the awareness that vocabulary should be presented in a more communicative way to facilitate vocabulary learning since it is essential for developing communicative competence. This positive perception to the use of CLT in teaching vocabulary is conducive for the actual classroom practice.In connection to this idea, Citing other researchers (Prosser, Trigwell and Taylor 1994;Williams and Burden, 1997 \& Patrick 2000), Kausar and Akhtar (2011) reported that teachers' beliefs or perceptions highly affect their classroom practice and any mismatch between perception and practice results in confused instruction over the student population.

In connection to these reflections, Karim (2004) stated that language teachers should always play the role of facilitator so that students will not be dominated by them when they practice the new language items. Richards and Rodgers (2001) on their part pointed out that vocabulary teaching in CLT focuses on meaning rather than form to achieve effective communication. For this purpose, the writers also advise the use of authentic materials in 
vocabulary teaching.

\section{Teachers' response to their Classroom practice in teaching vocabulary using CLT}

Based on the scores of table 2, the teachers have responded in item 4 and 12 that their practice is low level. However, in the rest of the 12 items, their response range is in medium level. Again from the grand mean 2.93, it can be deduced that the mean range falls in medium level. Generally from table 2, we can understand that the teachers did not practice CLT principles regularly (usually) to teach vocabulary lesson. Rather, they claimed that they practiced the expected activities sometimes. This was confirmed by the participants of the study during the interview that they claimed the use of some of the vocabulary teaching techniques like word parts, synonym, gesture, and definition.

More over, during the classroom observation, the researchers learnt that the vocabulary instruction was more of form-based approach (90\%) like telling the parts of speech and its meaning directly, which is devoid of meaningful communication; most of the teachers did not use participatory and task-based vocabulary instruction. They did not use instructional media, cross-word puzzles and group discussion to make the lesson interactive.

Generally, the instruction was more dominated by traditional form-focused instruction. According to Wang (2006), vocabulary should be presented in a more interactive approach using task-based language teaching with clear communicative goal to facilitate language acquisition.

Table two presents vocabulary teaching techniques which includes giving clues of the meanings of words, using collocation, guessing from context, discussing with friends, considering students' interest in the activities, using prefixes and suffixes, using interactive activities like role plays and games, using instructional media, and using synonyms and antonyms. Scholars in the field of language teaching support these types of interactive language teaching techniques and strategies. For instance, Larson, et.al (1984) and Jonassen (2001) emphasized the role of peer discussion in language classrooms. In relation to contextual guessing, Beglar and Hunt (2005) reported that guessing meaning from context is an important strategy that facilitates students' vocabulary acquisition. Using collocation is also considered as essential strategy to non-native learners to use English accurately (Miressa, 2014). Littlewood (1981) mentioned that role play helps students learn the language effectively to use it for meaningful communication.

\section{Teachers' Response to the problems in Applying CLT in Teaching Vocabulary}

The respondents indicated in table three that lack of students' interest, large class size, and difficulties of new words in the textbooks, lack of training in teaching vocabulary, and lack of time to finish textbooks as challenges they faced in vocabulary instruction using CLT. These are common problems observed most of the time in the EFL classrooms.

As part of the challenges mentioned by the teachers in the questionnaire, during the observation the researchers identified that the teachers were struggling with the large class size to present the lesson using communicative activities in the students' textbook. However, they were not effective in presenting the lesson in context to create meaningful interaction among students using the new words; also, the teachers did not use situations so that students can use word for dialogues.

The respondents also pointed out the prevalence and adverse effects of these problems on language teaching during the interview session. During the interview, they reported that the major student-related problems they faced in vocabulary teaching were large class size, students' poor background on vocabulary, and lack of students' interest to learn vocabulary. On average, there are 60-70 students per classroom which is not conducive for language learning to make it more student-centered. This also brings classroom management problems for language teachers (Huang, 2016).

Large class size is common in most of public schools throughout Ethiopia and it is considered as a burden not only for language teachers but also for other subject teachers; also it seems that due to the low weight given for vocabulary in tests and examinations, students do not pay attention to vocabulary study. In relation to teacherrelated problems, the participants hinted that they have lack of knowledge on how to apply CLT in teaching vocabulary. This calls for may be short term training to refresh them on current language teaching techniques. These results are consistent with the findings of other researchers in the field of language teaching; they have also reflected the negative impacts of these problems in the language teaching process (Sisay,2013; Huang, 2016).

\section{CONCLUSION}

The claim by the school and the teachers that English language teaching is conducted in a student-centered, communicative and interactive manner to improve the language skills of students is a mere rhetoric. EFL teachers have got strong perception to the use of CLT principles in teaching vocabulary; however, in practice they did not use them effectively in their classrooms due to various challenges like large class size, lack of knowledge on teaching techniques and low interest of students. The burden of large class size and voluminous textbooks to be finished in given time make the language teaching as a kind of work done business as usual, simply for reporting to higher level bodies as if things are going well at the grass root level. This is a form of wastage of public money without serving the desired goal of schooling. If things continue in such a way, there will be no improvement in 
the language skills in particular and academic achievement in general among the students. This situation needs attention of stakeholders to improve the teaching and learning process of English as a foreign language classes. Unless there is change in the testing, evaluation and teaching culture in line with the real purpose of English in the country, the communicative language teaching remains as a mere rhetoric and never operated ordinance in the schools. Hence, there should be strong political commitment on the side of the government to bring about practical changes in such public schools in the country.

Moreover, from this study one can understand that language teaching in the EFL settings is highly influenced by many factors that it needs concerted efforts of many stakeholders; thus, this study contributes a body of knowledge to the international readers to understand what is going on currently in EFL classes.

\section{RECOMMENDATION}

$\checkmark$ Teachers need to get on job practical training on how to use CLT in vocabulary teaching and other language skills development by the local school supervisors.

$\checkmark \quad$ The EFL teachers have to model students using both explicit and implicit vocabulary lesson so that students could be autonomous learners to study more by themselves. For example, students can engage in extensive reading and use language learning mobile applications for vocabulary study.

$\checkmark \quad$ It is necessary that large class size should be minimized to help classroom teachers use student-centered and individualized approach for effective language instruction.

$\checkmark \quad$ Local and international stakeholders have to work together to improve the conditions of public schools in English language instruction.

$\checkmark \quad$ The language teachers have to rethink about the wash back effect of language tests on students' approach to study vocabulary in particular and English language in general.

$\checkmark$ Other researchers need to have more studies on wider scale on the gap between teachers' perceptions and their classroom practices in the EFL classes.

\section{REFERENCES}

Abebe ,Y. (2009).Strategic for teaching vocabulary in four governmental Schools in Bahir Dar City. Thesis .BahirDar University.

Almalki, M. M.(2014). Teacher Perception of a Newenglish as a Foreign Language (EFL) Curriculum In Saudi Arabia, Unpublished M.A thesis, State University of New York. http://pdfs.semanticscholar.org.

Ansarey, D. (2012).Communicative Language Teaching in EFL Contexts: Teachers Attitude and Perception in Bangladesh. ASA University Review, Vol. 6 No. 1.

Beglar,A. \& Hunt,D. (2005).A framework for Developing EFL Reading Vocabulary, Reading in a Foreign Language, 17(1).

Brown,H.D.(2000). Principles of Language Teaching \& Learning. New York: Longman.

Brumfit, C. \& Johnson, K.(1979). The Communicative Approach to Language Teaching. New York: Oxford University Press.

Daniel, D.(2010). An Exploration into perceptions of Junior Secondary School English Teachers towards communicative language teaching and their actual Classroom practices grade 8 in focus, M.A. thesis, Addis Ababa university.

Fosch, M.C. (2017).The role of both teachers and students with a communicative approach . Catalunya. Faculty of Education Translation and Human Science, University of Victoria .

Huang,S.(2016).Communicative Language Teaching: Practical Difficulties in the Rural EFL Classrooms in Taiwan, Journal of Education and Practice, vol.7(24),pp.186--202. http:// www.iiste.org

Jonassen,D.H.(2001). Communication Patterns in Computer Mediated Versus Face to Face Group problem Solving. Educational Technology Research and Development, 49(1), 35-51.

Kausar, G. and Akhtar, R.N.(2011). Pakistani Students' and Teachers' Beliefs about English Language Learning at School Level: An Analytical Study, Journal of Education and Practice,2(5),pp.17-29. http:// www.iiste.org

Krashen, S. (1981). Second Language Acquisition and Second Language Learning. California, USA: Pergamon Press Inc.

Karim.K.M.R.(2004).Teachers perceptions ,attitudes and expectations about communicative Language Teaching in post- secondary education in Bangladesh. University of Victoria.

Larson,C.O., Dansereau, D.F., Donnell,A.O.,Hytthecker,V.,Ambitte,J.G.,\& Rocklin,T.R. (1984). Verbal Ability and Cooperative learning: Transfer of Effects, Journal of Reading Behavior, 16 (4),289-295.

Littlewood, W. (1981). Communicative Language Learning. Cambridge University Press.

Lu, D. (2017). Teachers' Beliefs and Practices: ESL Teachers' Perceptions of Vocabulary Instruction, Culminating Projects in English. 93. https://repository.stcloudstate.edu/engl_etds/93

Lynch, B. K. (1996). Language program evaluation: Theory and practice. Cambridge: CUP. 
McCarthy,M.J. (1990). Vocabulary. Oxford: Oxford university press.

Melaku, B.W (2019). Reconnoitering Teachers' Vocabulary Teaching Strategies: The case of Grade Nine Teachers' in Kokebe Tsibah Secondary and Preparatory School, Addis Ababa. International Journal of Academic Research Education Review, 7(5): 81-90 DOI: 10.14662/IJARER2019.125

Miressa, A. (2014) An assessment of The Practice of Vocabulary Teaching Strategies in EFL Classes Kellem Secondary School Grade 9 and 10 English Teachers in Focus , Jimma ;JU.

Nyzgi Kidane. (2016).Exploring EFL Teachers' beliefs \& practices of vocabulary teaching techniques. M.A.Thesis. Bahir Dar University.

Oxford, R. L. (1990). Language Learning Strategies: What Every Teacher Should Know. Boston: Newbury House Publisher.

Pamintuan,C.F., Mallari, D.G., Garcia, N.T., Galang, J.P., Buduan, R. M.(2018). The Use of WeChat Application on CFL Learners' Vocabulary Acquisition, TESOL International Journal,vol.13 (4),pp.26-38. http://www.tesol-international-journal.com

Richards, J. C., \& Rodgers, T.H.(2001).Approaches and methods in Language Teaching. USA: Cambridge University Press.

Richards, J.C. (2006). Communicative Language Teaching Today. Cambridge University Press.

Savignon, S. J. (2002).Interpreting Communicative Language Teaching: Contexts and Concerns. in Teacher Education. Yale: Yale University Press.

Shejabala, D. (2006). Methods and approaches in vocabulary teaching and their influence on Students' acquisition. Masaryk University.

Sharma,B.A., et.al. (2000). Research Methods in Social Sciences. New Delhi: Sterling publisher.

Sisay, T. (2013).Assessing the Challenges of Teaching Speaking Skills in a Large Classroom in Ethiopian Context, M.A thesis, Haramaya University.

Tadesse, K.(2016).Effectiveness of Communicative way of Teaching Vocabulary. M.A. Thesis. Bahir Dar University.

Yu-Ling, L.( 2005). “Teaching Vocabulary Learning Strategies: Awareness, Beliefs, and Practices. A Survey of Taiwanese EFL Senior High School Teachers", M.A. thesis (Unpublished). University of Essex.

Wang, C.(2006). Designing Communicative Tasks for College English Course, M.A. thesis, Chongqing Normal University \& Yangtze Normal University, China.

Wassihun, A. (2016). Assessing the practice of vocabulary teaching strategies in EFL Classes .Thesis, Debre Markos University.

Wilkins, D. A. (1976). Notional Syllabuses. Oxford: Oxford University Press.

List of tables

Table 1. Analysis of teachers' perception on CLT to teach vocabulary

\begin{tabular}{|l|l|l|}
\hline $\mathrm{s} / \mathrm{n}$ & Statements & Mean \\
\hline 1 & The classroom vocabulary activities should expose students for communicative practices & 3.8 \\
\hline 2 & The teachers role is a facilitator of vocabulary practices in classroom & 3.9 \\
\hline 3 & The tasks must give an emphasis on meaningful communication rather than form of vocabulary & 3.3 \\
\hline 4 & The teacher should use authentic materials in teaching practice of vocabulary & 4.2 \\
\hline 5 & The learners must be engaged in classroom vocabulary activities & 3.9 \\
\hline 6 & The teacher must be involved in classroom tasks of vocabulary lesson & 4.3 \\
\hline 7 & Effective teaching practice of teachers is involving students for actual practice & 4.7 \\
\hline 8 & Activities should be designed through exposing learners for real communicative practices & 4.6 \\
\hline & Grand mean & 4.08 \\
\hline
\end{tabular}

$\mathrm{N}=10$

Key: Strongly Agree $=\mathrm{SA}$, Agree $=$ Ag, Uncertain $=\mathrm{U}$, Disagree $=$ DA, Strongly disagree $=\mathrm{SD}$

Key: mean score interpretation (Oxford, 1990)1.00_2.49 low 2.5_3.49 medium 3.5_5.00 high 
Table 2. Analysis of teachers' practice to teach vocabulary using CLT

\begin{tabular}{|l|l|l|}
\hline No. & \multicolumn{1}{|c|}{ Questions } & Mean \\
\hline 1 & When you teach vocabulary, how often do you give clues for the meanings of the new word? & 2.9 \\
\hline 2 & $\begin{array}{l}\text { In your teaching practice of vocabulary, to what extent do you use collocations to teach the new } \\
\text { words? }\end{array}$ & 2.9 \\
\hline 3 & To what extent do you practice teaching vocabulary communicatively & 3.1 \\
\hline 4 & How often do you give the meanings of the new words before learners try? & 1.8 \\
\hline 5 & $\begin{array}{l}\text { How often do you give opportunities to your students to discuss with their peers in vocabulary } \\
\text { activities? }\end{array}$ & 3.3 \\
\hline 6 & How often do you give room for learners to find the meanings of new words from the context? & 3.4 \\
\hline 7 & In your teaching practice, how often do you use group discussion to teach new vocabulary? & 3.1 \\
\hline 8 & How often do you give activities based on learners' interest in teaching vocabulary? & 3.2 \\
\hline 9 & $\begin{array}{l}\text { When you teach, how often do you use prefixes and suffixes to teach the meanings of the new } \\
\text { word? }\end{array}$ & 2.8 \\
\hline 10 & To what extent your practice of teaching vocabulary gives a chance for communicative purposes? & 2.8 \\
\hline 11 & How often do you make vocabulary lesson interactive using role plays, games and conversation? & 3.3 \\
\hline 12 & In your teaching, how often do you use cross word puzzles to teach the new vocabulary? & 2.1 \\
\hline 13 & How often do you use instructional media to teach vocabulary? & 3.1 \\
\hline 14 & In your teaching, how often do you use synonyms and antonyms to teach vocabulary? & 3.2 \\
\hline & \multicolumn{1}{|c|}{ Grand mean } & 2.93 \\
\hline
\end{tabular}

$\mathrm{N}=10 \quad A l=$ Always (5) $U=$ Usually (4) $S=$ Sometimes (3) $R=$ Rarely (2) $N=$ Never (1)

Key: mean score interpretation (Oxford, 1990)1.00_2.49 low 2.5_3.49 medium 3.5_ 5.00 high

Table 3. Analysis of teachers' response to problems in applying CLT

\begin{tabular}{|l|l|l|l|l|l|l|}
\hline no & \multicolumn{1}{|c|}{ Statements } & \multicolumn{2}{l|}{ Yes } & \multicolumn{2}{l|}{ total } \\
\cline { 3 - 6 } & & $\mathrm{n}$ & $\%$ & $\mathrm{~N}$ & $\%$ & $\%$ \\
\hline 1 & Lack of training affects you to practice CLT in teaching vocabulary. & 6 & 60 & 4 & 40 & 100 \\
\hline 2 & $\begin{array}{l}\text { The tasks that are given on the text are too much to cover them in the given } \\
\text { time. }\end{array}$ & 6 & 60 & 4 & 40 & 100 \\
\hline 3 & The students are not interested in vocabulary lesson. & 8 & 80 & 2 & 20 & 100 \\
\hline 4 & $\begin{array}{l}\text { The large number of students affects you to apply CLT in teaching } \\
\text { vocabulary. }\end{array}$ & 8 & 80 & 2 & 20 & 100 \\
\hline 5 & I teach vocabulary equivalently with the other skills. & 8 & 80 & 2 & 20 & 100 \\
\hline 6 & $\begin{array}{l}\text { The difficulties of new words challenge you to apply CLT in teaching } \\
\text { vocabulary efficiently. }\end{array}$ & 8 & 80 & 2 & 20 & 100 \\
\hline 7 & $\begin{array}{l}\text { The preparations of vocabulary lessons affect you to practice CLT in } \\
\text { teaching vocabulary. }\end{array}$ & 6 & 60 & 4 & 40 & 100 \\
\hline
\end{tabular}

$\mathrm{N}=10$ 